\title{
UN DISEÑO VIRTUAL PARA UNA CAPACITACIÓN DOCENTE QUE PROMUEVA UNA CONFIGURACIÓN COLABORATIVA EN LA RECONSTRUCCIÓN E INTEGRACIÓN DE CONOCIMIENTOS
}

\author{
Mónica Gallino (Universidad Nacional de Córdoba)* \\ nvaleira@efn.uncor.edu \\ Maricel Occelli (Universidad Nacional de Córdoba)* \\ mariceloccelli@gmail.com \\ Nora Valeiras (Universidad Nacional de Córdoba)* \\ nvaleira@efn.uncor.edu
} Recibido: 28/07/2011 Aceptado: 26/10/2011

\section{Resumen}

La realidad social del siglo XXI nos enfrenta a numerosos retos en relación a la formación docente. Su nuevo rol, lleva a que su capacitación sea también un fuerte desafío. La ausencia de propuestas de capacitación disciplinar en el área de Biología nos motivó a diseñar, aplicar y evaluar un curso denominado "Plantas Transgénicas: Mitos y Realidades" para Profesores de Ciencias Biológicas y Químicas a través del Aprendizaje Basado en Problemas (ABP) y mediado por las TIC. El propósito de esta intervención fue generar una propuesta que potenciara intercambios y búsquedas de información desde diversas perspectivas a los fines de lograr una mirada holística de la complejidad de la temática. Es decir, no impostar información desde la transmisión sino desde la conformación de una verdadera comunidad virtual de investigación guiada, pero no estructurada, que permitiese suscitar interrogantes desde los mis-

* Doctora en Ciencias de la Educación. Universidad Católica de Córdoba. Licenciada en Ciencias de la Educación (especialización en Psicopedagogía Experimental). Universidad Católica de Córdoba.

* Magíster en Educación en Ciencias Experimentales y Tecnología. Facultad de Ciencias Exactas, Físicas y Naturales. Universidad Nacional de Córdoba. Profesora en Ciencias Biológicas y Bióloga. FCEFyN - UNC.

* Doctora en Educación en Ciencias. Universidad de Burgos, España. Magíster en Educación en Ciencias. Alcalá de Henares, España. Profesora en Ciencias Naturales. Facultad de Ciencias Exactas, Físicas y Naturales. UNC. 
mos participantes y llegar a consensos de manera independiente. El objetivo de este trabajo se centra en mostrar cómo un diseño de formación puede provocar procesos cognitivos creativos en la reconstrucción e integración de conocimientos en entornos virtuales de enseñanza y de aprendizaje.

\title{
Palabras claves
}

Estrategias Didácticas - Virtualidad - Colaboración - Procesos Cognitivos - Investigación guiada.

\section{VIRTUAL DESIGN FOR A TEACHER TRAINING THAT PROMOTES A COLLABORATIVE CONFIGURATION IN THE RECONSTRUCTION AND INTEGRATION OF KNOWLEDGE}

\begin{abstract}
The social reality of the XXI century confront us to many challenges about training teacher. The teacher's new role also makes your training be a challenge. The lack of disciplinary training teacher proposals in the Biology area motivated us to design, apply and evaluate a course called "Transgenic plants: myths and realities". Biology and Chemistry teachers participated as students in the course. The proposal used Problem Based Learning (PBL) and mediating structures, based on Information Technology and Communication (ITC), were also used. The aim of this proposal was to foster the exchange and bibliographic search from different perspectives in order to achieve a holistic view of the complexity of the subject. That is to say, not impose inforamation through transmition but through from the formation of a true guided virtual research community. This comunity is not structured and allows that the students to ask questions and building agreements through an independient way. The aim of this papers is to show how a formative design can promote creative cognitive processes in the reconstruction and integration of knowledge in virtual teaching and learning.
\end{abstract}

\section{Key words}

Didactic Strategies - Virtuality - Colaboration - Cognitive Process - Guide Research.

\section{Introducción}

En el mundo actual en el que la globalización se ha impuesto, el trabajo interdisciplinario se ha generalizado y las Tecnologías de la Información y de la Comunicación (TIC) han avanzado sobre todos los aspectos de la vida social. Se requiere de individuos capacitados para que en el marco de tal contexto, puedan encontrar soluciones a los problemas que la sociedad enfrenta. Por esto, en la formación de los docentes es clave la incorporación de ofertas educativas en entornos virtuales. 
La realidad social del siglo XXI, nos enfrenta a numerosos retos en relación a la formación docente. Su nuevo rol, la necesidad de que se capacite para atender a la diversidad en un contexto cambiante, lleva a que su capacitación sea también un fuerte desafío. A su vez, este reto se profundiza aún más ante ciertos conocimientos científicos tecnológicos controversiales, como por ejemplo los desarrollos biotecnológicos (Levinson, 2006).

La ausencia de propuestas de capacitación disciplinar en el área nos motivó a diseñar, aplicar y evaluar un curso denominado "Plantas Transgénicas: Mitos y Realidades" (Occelli, Garcia, Biber y Valeiras, 2009) para Profesores de Ciencias Biológicas y Químicas a través del Aprendizaje Basado en Problemas (ABP) y mediado por las TIC. El curso se planteó con una duración de ocho semanas totales y con cinco horas semanales aproximadas para la realización de las tareas propuestas y la participación en espacios de comunicación. Intervinieron 75 docentes en actividad en el nivel medio, provenientes tanto de nuestro país como del Uruguay, y el curso estuvo coordinado por dos tutores.

El propósito de esta intervención fue generar una propuesta que, apoyada en el ABP y en los principios de la Enseñanza para la Comprensión $(\mathrm{EpC})$, potenciara intercambios y búsquedas de información desde diversas perspectivas a los fines de lograr una mirada holística de la complejidad de la temática. Es decir, no impostar información desde la transmisión sino desde la conformación de una verdadera comunidad virtual de investigación guiada, pero no estructurada, que permitiese suscitar interrogantes desde los mismos participantes y llegar a consensos de manera independiente. Entendiendo esto último como "desprendidos" de la "mano" del docente, en un proceso autogestionario de grupo.

Los interrogantes que mediaron el planteamiento inicial versaron acerca de aspectos que permitieran una toma de decisiones tecno-pedagógicas en las cuales se lograra superar las propuestas reduccionistas en materia educativa con estos entornos. En este sentido se cree importante centrar el interés en el planteo educativo sin sobrevalorar el poder de la herramienta tecnológica sino como integrada didácticamente y destacando la dimensión de mediación. En este recorrido, nos hemos preguntado: ¿Sobre qué principios plantear un diseño formativo en entornos virtuales que favorezca la construcción de conocimientos significativos? ¿Qué criterios son necesarios tener en cuenta en las propuestas de capacitación docente en estos entornos? ¿Qué sucede en cursos de formación de formadores, cuando se les invita a trabajar en estos entornos y colaborativamente?

El objetivo de este trabajo se centra en mostrar cómo un diseño de formación fundamentado en el Aprendizaje Basado en Problemas (ABP) puede provocar procesos cognitivos creativos y de configuración colaborativa en la reconstrucción e integración de conocimientos más allá de lo prescripto en entornos virtuales de enseñanza y de aprendizaje. 


\section{Principios orientadores de la propuesta}

Partir de una propuesta que potencia la construcción de conocimientos mediados por tecnologías, implica concebirla de manera coherente con la concepción de aprendizaje. Desde el sentido común, el nexo entre enseñanza y aprendizaje es tan íntimo que la comprensión de un proceso parecería suponer la del otro. Reflexionar en este binomio es una categoría fundamental de nuestras prácticas, porque cuando uno diseña y desarrolla una situación de enseñanza lo hace pensando en la construcción de conocimientos dentro de un campo disciplinar en términos de posibilitar aprendizajes significativos (Forestello y Gallino, 2009).

Esta postura compromete a superar las posiciones instrumentalistas para dejar paso a una postura reflexiva que centralice su actividad en los aprendizajes como procesos situados. Es también revalorizar no solo el contenido sino el conocimiento didáctico del contenido. Este conocimiento es la categoría que, con mayor probabilidad, permite distinguir entre la comprensión del especialista en un área del saber y la comprensión del especialista que también educa. Entonces, cuando se trabaja en ambientes de aprendizaje mediados por tecnologías es de importancia centrar la atención en que si bien hay distancia física, no la hay desde el punto de vista cognitivo. Esto es así, dado que la relación educativa se presenta simbólica y tecnológicamente mediada.

Desde la perspectiva simbólica, una herramienta clave es el lenguaje, que desde diversas formas y estilos léxicos crea senderos para que el pensamiento los recorra. Las palabras enseñan conceptos, y en esta realidad virtual que también es textual, las palabras son hechos. El ordenador permite conexiones hechas de y transformadas por lenguajes. Sitúa al participante en la situación de codificar y decodificar signos desde construcciones sociales simbólicas en la mayoría de las veces en situaciones diferentes. Es importante entonces, plantear un diseño de formación que ancle en el "lenguaje del pensamiento". Es pensar la enseñanza y el aprendizaje en torno al significado y a los procesos mediante los cuales se crean y se negocian los significados en sociedad pero desde un contexto situado.

Esto nos remite a la noción de un sujeto configurador, en el cual el lenguaje permite tal construcción al "hablar de algo", estableciendo distinciones basadas en la significación, un algo que es aún hasta cierto punto una realidad externa. Es concebir al lenguaje como significante de la experiencia, donde el conocimiento y la realidad se construyen en interacción con otros individuos en un contexto compartido.

A su vez, según la conocida afirmación de Vigotsky (1988 a, 1988 b), no toda interacción promueve desarrollo, sino solo aquella que precede y que demanda esfuerzo cognitivo, paso decisivo para la comprensión. En este sentido, la decisión acerca de la selección del ABP como estrategia didáctica cobra 
centralidad en tanto responde a los criterios de ser potenciadora de procesos cognitivos complejos, integrando la construcción social del conocimiento.

La significatividad del problema impone su valor formativo en tanto se sustenta en el desequilibrio que se produce cuando los conocimientos previos resultan insuficientes para responder a una circunstancia planteada, es decir que permite interactuar en situaciones concretas y reveladoras estimulando -a partir de un conflicto cognitivo- a confrontar los propios esquemas con los de otros y modificarlos para construir nuevo conocimiento. En este contexto, no debemos olvidar que, cuando se afrontan problemas, no solo se piensa con otros sino también con herramientas artefactuales y simbólicas (Rodríguez Arocho, 2001). Esto resalta la importancia del efecto de los residuos cognitivos que, vinculado con el intercambio con tecnologías, se caracteriza por la profundización en los compromisos mentales que el individuo asume en su modo de operar con ellas. No sólo de acceso y conectividad sino de transformación del valor de la información para la toma de decisiones, así como la posibilidad de su incorporación a partir de la novedad (Escudero, 2009).

En síntesis, la cognición debe concebirse como culturalmente mediada y -al decir de Pea (1993)-, distribuidas en soportes, en la interacción con otros y en un contexto situacional. Para ellos son importantes cuatro dimensiones de la cognición que nos ayudan a las decisiones didácticas para nuestro planteo: cuál es el conocimiento presente, cómo se lo representa, cómo se lo recupera y cómo se lo construye (Salomon, 1993). Las dos primeras atienden a las funciones ejecutivas -específicamente distribuidas-, y las dos últimas a las funciones de orden superior -internas "en solitario"-.

Este reconocimiento, nos lleva también a preguntarnos acerca de la "situación" de los contenidos, es decir qué relevancia tienen en un planteo didáctico que busca la construcción significativa de los conocimientos. Al respecto Gimeno Sacristán (2005) afirma "los contenidos no son metas sino materiales para hacer competentes a quienes aprenden". Por lo cual nos importa de qué manera presentarlos a fin de que siendo materiales e información, se transformen en conocimientos. Esto lleva a la necesidad de proponer un diseño con estrategias de enseñanza y de aprendizaje que enfoquen la materia de estudio como un campo cultural en el cual el saber reside atendiendo a lo que es problemático y controvertido; "la metamateria, los consensos y disensos que hay en ella. Que el conocimiento es algo contextualizado social e históricamente. Hacer obvio el sentido del mapa que constituye cada campo del saber: las interrelaciones, los préstamos entre materias, la interdisciplinariedad" (Gimeno Sacristán, 2005).

Es en este sentido que el formato del ABP se integra como propuesta didáctica en tanto no implican un camino único para llevar adelante los procesos, basándose en argumentos convincentes y que se reconstruyen de una forma particular en situaciones de interacción. A través del ABP se espera que el alumno apele significativamente a sus conocimientos previos, a que reconstruya 
los significados implicados en el problema presentado y contextualizados en una realidad. Se busca que se enriquezcan con nuevos significados y sentidos, utilizando la memoria -residuo cognitivo-, pero no como almacenamiento sino como reconstrucción comprensiva.

Cuando se plantea resolver situaciones problemáticas en base a una dinámica de trabajo colaborativo, con riqueza de material curricular y también se crean las condiciones óptimas motivacionales, las estrategias de aprendizaje que se promueven son muy productivas; éstas superan ampliamente la tradicional repetición, la aplicación de algoritmos en la que se apela a la memoria fundamentalmente.

Existen numerosas investigaciones que dan cuenta que el trabajo colaborativo tiene efectos positivos en el rendimiento académico de los alumnos tales como adquirir, retener y transferir conocimientos, construir reglas, conceptos, principios y también mejorando sus relaciones socioafectivas como respeto mutuo, solidaridad, capacidad para entender otras perspectivas diferentes (Diaz Barriga y Hernández Rojas, 2001). Todas estas habilidades son necesarias para que el aprendiz las ponga en juego mientras realiza el proceso de resolución de problemas.

\section{El foco de análisis: las interacciones y los procesos dinámicos de reorganización}

En este apartado nos interesa destacar cómo a partir de las conceptualizaciones inicialmente desarrolladas, se pone en marcha una propuesta didáctica que hace hincapié en las interacciones autogestionarias de una comunidad de aprendizaje a partir de la resolución de un problema desde la simulación de miradas interdisciplinarias.

Se configura un aula virtual en plataforma Moodle, que a partir de la temática sobre los transgénicos, se problematice desde la discusión, reflexión y clarificación de sus "mitos y realidades". Para ello, se organiza el proyecto analizando reflexivamente los recursos que ofrece la plataforma y su pertinencia: Presentación general, en la cual quedan claramente explicitados los objetivos y el programa, el cronograma didáctico y las orientaciones generales de trabajo; Ejes didácticos que combinan la explicitación de la situación problema; Diferentes roles que se adjudican los participantes para el análisis y resolución del mismo; La hemeroteca; Los foros grupales modelizados con diferentes estrategias; Wikis y Chat (Tabla 1). 
Tabla 1: "Diseño y recursos utilizados para la capacitación" (Occelli y Vázquez-Abad, 2010).

\begin{tabular}{|c|c|c|}
\hline Actividades & Modalidad de Trabajo & Recursos Utilizados \\
\hline $\begin{array}{l}\text { Cuestionario inicial } \\
\text { (pre test) }\end{array}$ & Individual & Cuestionario \\
\hline $\begin{array}{l}\text { Análisis y discusión } \\
\text { de noticias periodísticas }\end{array}$ & Todo el grupo de Alumnos & Foro abierto \\
\hline $\begin{array}{l}\text { Presentación del problema } \\
\text { y asignación de roles }\end{array}$ & Grupos de origen & Foro privado \\
\hline $\begin{array}{l}\text { Exploración del problema } \\
\text { (meta- análisis) }\end{array}$ & Grupos de origen & $\begin{array}{l}\text { Foro privado } \\
\text { Wiki privada }\end{array}$ \\
\hline $\begin{array}{l}\text { Análisis de nuevas } \\
\text { fuentes bibliográficas }\end{array}$ & Grupos de origen & $\begin{array}{l}\text { Foro privado } \\
\text { Wiki privada }\end{array}$ \\
\hline Discusión entre pares & $\begin{array}{l}\text { Discusión entre los } \\
\text { participantes que } \\
\text { comparten el mismo rol }\end{array}$ & Foros según el rol \\
\hline $\begin{array}{l}\text { Discusión y planteo de } \\
\text { posibles soluciones }\end{array}$ & Grupos de origen & $\begin{array}{l}\text { Foro privado } \\
\text { Wiki privada }\end{array}$ \\
\hline $\begin{array}{l}\text { Construcción de una } \\
\text { solución de manera } \\
\text { colaborativa }\end{array}$ & Grupos de origen & $\begin{array}{l}\text { Foro privado } \\
\text { Wiki privada }\end{array}$ \\
\hline $\begin{array}{l}\text { Compartiendo y } \\
\text { discutiendo las } \\
\text { soluciones }\end{array}$ & Todo el grupo de alumnos & Foro abierto \\
\hline $\begin{array}{l}\text { Elaboración de una } \\
\text { propuesta didáctica }\end{array}$ & Individual & Tarea \\
\hline $\begin{array}{l}\text { Ensayo } \\
\text { (análisis metacognitivo) }\end{array}$ & Individual & Tarea \\
\hline $\begin{array}{l}\text { Cuestionario final } \\
\text { (Post test) }\end{array}$ & Individual & Cuestionario \\
\hline
\end{tabular}


Los grupos de trabajo están compuestos por cuatro integrantes con un rol definido para el abordaje: Consultor de genética, Asesor de una Cooperativa de granos, Representante de una Junta Médica y Representante de una Asociación Ambientalista. Según estos roles autoasignados, cada participante trabaja colaborativamente en su grupo cumpliendo una misión específica para resolver el problema. Se invita a los estudiantes (docentes en nuestro caso) a replantear el problema a través de un metanálisis guiado con las siguientes preguntas: ¿Qué sé en relación a este problema? ¿Qué necesito saber para resolver el problema? ¿Cómo puedo encontrar la información que necesito? ¿Qué ideas se me ocurren para resolver la situación problemática? (Occelli y Vázquez-Abad, 2010).

Sin duda, este planteo invita a la configuración de una comunidad de aprendizaje ya que se relaciona con la idea de un grupo de personas con diferentes niveles de experiencia y/o conocimiento, que aprenden gracias a las relaciones que establecen entre sí, en la negociación y el tipo de ayudas que se prestan mutuamente. Por otra parte, en estos entornos virtuales, cobra especial interés no solo el compromiso con el aprendizaje como objetivo explícito de la comunidad, sino también el uso de las tecnologías digitales para el desarrollo de la acción educativa intencional y cómo estas afectan a la dinámica y al consenso.

La manera en la que se plantea la configuración colaborativa y cogestionaria del trabajo implica para los participantes un reajuste de miradas y reflexiones, un debate y búsqueda constante no solo de información sino también de consenso en y con el grupo, en y consigo mismo, es decir con sus propios esquemas de pensamiento, dado que la capacitación se estructuró en función de la resolución, en grupos de trabajo, de una situación problemática abierta en la cual se integran actividades de indagación y debate en Foros que implican mixtura de intercambios en grupos entre pares (rol homogéneo) y grupos interdisciplinarios.

Para el análisis de cómo este diseño de formación impacta en el desarrollo de procesos cognitivos creativos y de configuración colaborativa se tienen en cuenta los siguientes aspectos:

a. Modos de autogestión: cómo se realiza la estructura de los grupos, cómo se realizan los acuerdos, cómo se interpreta la consigna, qué tipos de ayudas se observan como intervenciones de andamiaje y desde quienes (¿tutor?, ¿alumnos?) y cómo resuelven los conflictos.

b. Calidad de las aportaciones individuales: qué roles se ejercen desde ausencia-presencia del tutor, qué tipo de aportes se observan tanto desde la búsqueda de la información, como de la discusión y el consenso, cómo se reciben e interpretan los aportes, qué residuos cognitivos se presentan como evidentes y a través de qué instancias. 
c. Calidad del conocimiento construido colaborativamente: en este aspecto es necesario tener en cuenta los patrones de la «negociación de una acción», el conjunto mínimo de intercambios que son necesarios para que las partes alcancen un acuerdo sobre lo que hay que decir, pensar o hacer, y dentro de ello se distinguen tres dimensiones: qué, cómo y quién.

\section{a. Modos de autogestión}

En la distribución de los roles, cada miembro de los grupos deben auto asignarse, y este proceso se muestra como fuente de ansiedad. Las comunicaciones asincrónicas y la necesidad de definir en el plazo convenido previamente en el cronograma y en las consignas de trabajo, muestra las inseguridades de cada miembro generando situaciones de negociación, a veces conflictivas. Sin embargo, son los mismos alumnos quienes median en la resolución. El temor a la soledad y al desconocimiento de las miradas desde roles interdisciplinarios hacen que no se advierta en un primer momento la situación novedosa de aprendizaje planteada desde la propuesta didáctica, lo cual genera desconcierto. Algunos mensajes enviados entre los estudiantes de un grupo dan cuenta de esta situación:

Hola Laura, creo que es mejor que decidas qué querés ser, y yo te sigo, eligiendo un rol. Falta el varón, no recuerdo el nombre. Pero le dejamos el rol que sobre, si no llega antes a la elección definitiva. Una vez elegido no sé cómo continuamos... Estamos medio perdidas...ayuda!! (Ester)

Me parece bien. Visto y considerando que las demás chicas no se decidieron y que hoy es el cierre en la designación de roles, yo me propongo para representante del comité directivo de una fundación. Laura, Ester, no lo tomen arbitrario, pero hay que decidirse, si alguna tiene algún problema con los roles que quedan, por favor comuníquense que voy a estar revisando el foro y lo hablamos. Es difícil ponerse de acuerdo en foros, no es cierto? Un saludo a todos. (Luis)

Y sí, no es fácil comunicarse en un foro. Pero creí que era bueno que cada uno expresara su opinión para elegir el rol, y no que a horas de terminar el plazo, Luis de forma tajante lo decidiera. No soy experta en Genética pero asumiré el rol, si les parece (Laura).

Continúan las intervenciones...

...Por otro lado, (se dirige a la Tutora), creo que el problema no fue que Laura no encontrara eco, todos participamos y nos comunicamos, sino que cada uno fue muy ambiguo y nadie propuso un rol hasta último momento. Ese fue el problema. Creo que al sentirse sola, Laura debió manifestar su preocupación al grupo asumiendo un rol si quería acelerar el trámite, en lugar de decírtelo a vos. Eso fue infantil y generó incomodidad. Las respuestas estuvieron, varias $y$ dentro de la fecha límite, por algo se establecen las mismas. Y creo que hay que ser mas tolerantes como vos decís pero también adultos. Creo que todos 
expresamos lo que sentimos y ahora podemos pasar a la siguiente actividad. Saludos a mis compañeros de grupo, nos vemos en la wiki (Ester).

... Bueno grupo, he leído y re-leído los últimos mensajes. Realmente creo que no hubo malas intenciones de nadie. Nosotras, como tutoras, entendemos que a veces ustedes no se puedan conectar, pero también comprendemos que del otro lado, hay otros integrantes del grupo, esperando respuestas. Como les dije antes, tratemos de mantener la cordialidad, y tratemos también, de que las comunicaciones se den a través del foro. Así los podemos guiar, podemos detectar errores y problemas, etc. Saludos, (Tutora).

El diálogo transcripto pone en evidencia que las pistas de ayuda de la tutora fueron oportunas pero no continuas, de manera tal de dejar que el mismo grupo resolviese la situación. Esto produce un paso de la individualidad a la conformación de pautas básicas de interacción con la finalidad de lograr una identificación como comunidad de trabajo y aprendizaje. La tolerancia a los ritmos personales y a los "tonos" que se expresan en el texto escrito, a los diferentes estilos de escritura, merecen una interpretación que va más allá de lo leído, o expresado. Es decir, las interpretaciones subjetivas remiten primero a sujetos imaginarios, donde no se rebasa lo textual hacia el "otro", es necesario establecer pautas previas de conocimiento sobre estilos personales para poder configurar una relación productiva. En ese momento, los alumnos se convierten en mediadores y co-constructores de la búsqueda y resolución del problema. Estas estrategias de intervención desde la no-intervención didácticamente planteada promueve dinámicas no rutinarias y una adopción de roles más operativos, en dónde los andamiajes son implementados desde el seno del mismo grupo en colaboración.

Esta comunidad de trabajo también resuelve dudas referidas a los nuevos recursos tecnológicos y a la modalidad de trabajo. Por lo tanto los estudiantes buscan en primer lugar la ayuda de sus compañeros de grupo. El comentario de Carlos ejemplifica esta situación:

Disculpen mi ignorancia. Si yo escribo en el cuadro, debajo de lo que hizo María, ¿eso le llega a todas? ¿O debo hacer alguna otra cosa? ¿Cómo entro en la Wiki? Desde ya gracias por la paciencia (Carlos).

Asimismo, son los mismos alumnos quienes se autorregulan, reinterpretando las consignas de trabajo y los objetivos de cada tarea propuesta. Los siguientes comentarios extraídos de dos grupos diferentes dan cuenta de este tipo de regulación:

.... me parece ordenado discutir en el foro, pero las preguntas las tenemos que contestar entre todos. Qué te parece si después de discutir escribimos directamente en la wiki. Allí podemos modificar, borrar, etc, tranquilos porque 
todo seguirá guardado. Con respecto a la primer pregunta, te referís a ¿qué sabemos del tema?, ¿la primera del cuadro?, si es así completalo con tus aportes. Estoy de acuerdo en que cada uno lo tiene que hacer desde su rol, pero igual tenemos que lograr una construcción grupal. Esperemos también los aportes de los otros integrantes. Además tenemos que tener en cuenta los plazos, para completar el cuadro y escribir el párrafo entre todos tenemos plazo hasta mañana, un día especialmente complicado para mí. Cariños (Mirta).

...Tendríamos que buscar tres o cuatro de los textos, indicar la fuente, decir porqué los elegimos y después elaborar un informe integrado. De alguna manera tendremos que hacer el trabajo del rol de representante de Cooperativa de granos porque (Tutora) me dijo que no van a ponernos un cuarto integrante si Adriana no vuelve (Carla).

Por otro lado, los estudiantes valoran el espacio de comunicación como posibilidad para aprender de una manera diferente sin la presencia de un docente como autoridad del conocimiento, sino como guía del proceso de aprendizaje logrado de manera colaborativa entre los integrantes del grupo. Los siguientes comentarios extraídos de entrevistas realizadas a los estudiantes ponen en evidencia este sentir:

...tuve la posibilidad de leer varios artículos interesantes sobre el tema. Ya sean a favor como en contra de los OGM. Pero igual que lo más rico del curso, es la discusión que se plantean en los foros, el intercambio de opinión es lo que más me ha hecho aprender en el curso (Celene)

...La relación con el conocimiento compartido es medio lento, ya que estamos acostumbrados a tener el último guiño del profesor (Ana)

...en lo que respecta a la modalidad me gusta porque estoy todo el tiempo pensando que me contestaran mis compañeros y qué nuevo aporte puedo hacer! te atrapa... (Mariana)

\section{b. Calidad de las aportaciones individuales}

Las relaciones que se manifiestan rebasan el hecho en sí y llaman a una configuración de espectros más amplios que muestran la intensa búsqueda no solo de información sino de aquellos aspectos que cada uno posee desde la propia experiencia y de los "residuos cognitivos".

(luego de realizar cuatro aportes conceptuales concluye...) Como podrás ver estas "divagaciones biológicas de un haragán" (Hay una novela que se llama Divagaciones de un haragán), que pretenden ser razonamientos en base al conocimiento incompleto que humildemente manejo, me hacen pensar, a pesar de las dudas, que no puede ser el polen sino otra cosa como algún/os agroquímicos de los tantos que se usan para variadas situaciones. 
Es precisamente en estos puntos básicos en los que me voy a fundamentar para recomendar, como integrante de una Fundación, al Intendente para que reoriente a los demandantes en cuanto a la búsqueda de otras causas para las malformaciones (Francisca).

Hola Adriana, hoy a la tarde voy a leer con detenimiento de nuevo lo que nos mandaste, realmente está jugoso. Bueno, hay algo que quería comentarte con respecto al descubrimiento de Watson y Crick: en primer lugar no incluyeron en el informe los trabajos de una investigadora que murió muy joven de cáncer de mama, no tenía 40, que se llamó Rosalind Franklin y que les abrió el camino a ellos ya que con sus estudios con $R X$ aparecía la estructura en doble hélice del DNA y en segundo lugar con lo que se sabe ahora hay que remitirse a la rama de la genética que es la epigenética donde se ven muchas cosas claramente con estudios muy profundos sobre genes y el ambiente, por ej como una hambruna cambia totalmente la forma de actuar de ciertos genes. Sería largo de explicarte aquí. Después a la tarde con más tiempo les voy a mandar un artículo científico, que se llama Genes y Memes muy interesante como para ir metiéndose en la epigenética que algo tengo también pero no se por donde. También hay que tener en cuenta que no se puede pensar que con algo que se descubre, todos ustedes lo saben y se puede considerar definitivo, mirá lo del Dogma de la Biología que lo de dogma les duró hasta que descubrieron los retrovirus que no "copian" del DNA sino del RNA (Amalia).

Hola gente: Veo que soy el único que está a favor de la tecnología de OGMs y hoy lo confirmo; en pos de respetar el mecanismo del curso indagué en los documentos que están en la biblioteca de esta aula y me encontré con que todos o casi todos son documentos Anti-OGM!! Yo sinceramente veo una clara inclinación en contra de los OGM y la verdad, lo repito, me siento sapo de otro pozo y estoy empezando a creer que mis aportes no van a tener mucho sentido. Sepan disculparme pero voy a buscar y proponer otros artículos y también voy a aportar datos que me proporciona una Licenciada en Biología que trabaja en un laboratorio del INTA y les digo la verdad, sabe un tocazo de esto!!! Por lo tanto, trataré de ser más objetivo e intentaré mostrar el lado positivo de los OGM porque creo en ello, de ahí a lo que hagan las empresas en pos de sus conveniencias económicas, eso ya es otra cosa y se sale de lo netamente científico, que es lo que realmente me interesa. Espero no haber sido grosero, no es mi intención. Saludos (Luis).

Hola a todos: Yendo un poco a lo que nos pidió la tutora. Según veo en todos los grupos hemos llegado a la conclusión de que no existen evidencias científicas que avalen lo propuesto en la carta al intendente. Como "genetistas" no pudimos demostrar que el grano de polen ingrese en el organismo humano y que posteriormente se transmita a la descendencia provocando malformaciones 
congénitas. Pero si llegamos a la conclusión, ya que la bibliografía lo avala, que los agroquímicos en general y los herbicidas en particular producen alteraciones, causantes de las malformaciones congénitas. Por otra parte al hablar de malformaciones congénitas nos estamos refiriendo a modificaciones que se realizan en el embrión o el feto durante su gestación, y los agroquímicos está comprobado que lo alteran, pero no existe a la fecha nada que yo haya leído que demuestre que el polen, pueda causarlas. Debería haber algún mecanismo que permita que el transgén llegue a la la sangre de la madre embarazada y que por vía placentaria pase al futuro bebé. Pero de esto no he encontrado nada que lo avale (Marta).

Es aquí en dónde se manifiestan los procesos de reelaboración de conceptos mediados por la estructura cognitiva de cada participante. La calidad de los procesos de reconstrucción, se configuran como clave fundamental para la calidad del aprendizaje. Por un lado, la estructura lógica de los contenidos adquiere significatividad en los procesos que desde la propia situación personal y de los conceptos ya presentes, permiten poner en relación de manera sustantiva y no arbitraria, de manera profunda y no superficial, los nuevos conocimientos. Podemos observar que las representaciones desde los alumnos, son representaciones sobre el sentido que tiene para él aprender ese contenido, sobre los motivos para hacerlo, las necesidades que ese aprendizaje cubre y las consecuencias que supone para la percepción de uno mismo como aprendiz.

\section{c. Calidad del conocimiento construido colaborativamente}

Hablar de trabajo colaborativo, interacción, ó actividad conjunta, implica el hecho de que tutor-alumnos-alumnos actúan el uno para el otro y entre sí, de manera que las actuaciones de cada participante sólo se entienden y cobran significado en el marco de, y en referencia a, las actuaciones del resto de participantes (Onrubia, 2005).

Este proceso adquiere cierto grado de complejidad en los entornos virtuales donde es necesario superar las visiones individualistas para gestionar un consenso. La docencia presencial en general, configura un estilo de docente centrado en la persona individual, en decisiones sobre la práctica de enseñanza que son más bien marcadas desde la experiencia y trayectoria de cada uno en una estructura propia de la enseñanza media, compartimentalizada. Recordemos que nuestros alumnos, son docentes de este ciclo. Las resistencias, como los entusiasmos, se hacen presentes.

En relación a los aprendizajes obtenidos en el trabajo colaborativo observamos que los alumnos valoran sus aprendizajes conceptuales, pero también destacan que la metodología del curso les abrió un nuevo panorama en cuanto a cómo trabajar en grupo y resolver situaciones, y en este proceso se destaca a la interacción entre los pares como un factor clave. Los siguientes comentarios realizados durante las entrevistas a los estudiantes permiten ejemplificarlo: 
"Esto de compartir experiencias e información con otros docentes me parece muy positivo, ya que uno lo puede aplicar en el aula con sus propios alumnos" (Ana).

"Es la primera vez que participo de un Foro activo, y (a pesar de mis demoras) en la construcción colaborativa de una solución a un problema potencialmente real, aunque mas que construir una solución me pareció que fue la construcción de un análisis final. Rescato que el intercambio de opiniones no fue solamente eso, sino ayudarnos a entender racionalmente el tema para tomar posturas y acciones responsables" (Carmen)

"Pero igual que lo mas rico del curso, es la discusión que se plantean en los foros, el intercambio de opinión es lo que más me ha hecho aprender en el curso" (Marta)

“...en relación a los contenidos te soy sincera hay mucho por aprender y me parece que me deja inquietud para buscar mas información, aunque ahora con criterios mas sólidos, estoy demasiado ansiosa por saber siempre más" (María)

“...la relación con el conocimiento compartido es medio lento, ya que estamos acostumbrados a tener el último guiño del profesor, tengo que sacarme alguna ropa vieja que tengo puesta, y aprender esta nueva forma de aprender (no en soledad) sino en foros y en wikis, en lo que respecta a la modalidad me gusta porque estoy todo el tiempo pensando que me contestaran mis compañeros y que nuevo aporte puedo hacer!! te atrapa" (Adriana)

“...es la primera vez que hago un curso on-line por ello destaco primero lo relacionado con la participación de los foros, la wiki. Este aspecto me resulto interesantísimo. Las discusiones en los foros son muy ricas hay mucho para aprender y compartir. Por otro lado la responsabilidad que implica cumplir con las tareas y sobre todo cuando se realizan en grupo" (Luis).

Los procesos de metacognición, son relevantes para posibilitar la regulación de los aprendizajes y los conflictos que se puedan ir presentando. Es importante el trabajo del tutor, como mediador, que orienta pero sabe esperar los tiempos necesarios para la producción de la gestión grupal. En este sentido, la resolución de problemas como estrategia didáctica permite configurase también, como un medio para desarrollar la capacidad de aprender a aprender colaborativamente en estos entornos. 


\section{Reflexiones finales}

Se considera como acierto la propuesta del diseño didáctico enmarcada en una línea constructivista que busca que los aprendizajes de los participantes sean significativos y autogestionados en un proceso de trabajo colaborativo, asumiendo como estrategia, el aprendizaje basado en problemas (ABP). En este sentido los ejes didáctico, tecnológico y de diseño se articulan en la solución de un problema complejo y abierto.

Estos elementos permiten articular la tendencia constructivista y particularmente de aprendizaje significativo con las acciones de problematización de las prácticas de los docentes y de su visión crítica sobre su propio quehacer y las implicaciones que tiene el uso y apropiación de estas tecnologías, en los procesos de enseñanza y aprendizaje.

Asimismo, la posibilidad de proponer diferentes rutas que buscan un mismo objetivo, de asumir el reto del aprendizaje como la oportunidad para resolver una situación que es de interés para un grupo, consolidan al $A B P$, como una estrategia fundamental para potenciar los aprendizajes de los participantes del proyecto a través del uso y apropiación del computador e Internet. Es también otorgar un mayor protagonismo al participante. Por otro lado, el diseño de propuestas en las que se configuran roles referenciales para la búsqueda de información, y procesos circulares para resolver desde miradas diversas una misma situación problemática, incide en la ruptura de enfoques unidireccionales, rompe la rutina cotidiana de los saberes compartimentalizados para abrir a nuevas miradas más interdisciplinarias y de esta forma, evitar los reduccionismos de la especializaciones. Esto en sí mismo es ya un valor agregado.

La figura del tutor como una presencia constante, pero que no da respuestas conclusas sino que sabe esperar y posibilitar la gestión grupal, la búsqueda independiente de información, la reconstrucción significativa de conceptos y la solución de obstáculos y decisiones del grupo participantes, se vuelve central.

La implementación implica primero una clarificación pedagógica y en segundo lugar, la integración tecnológica desde una actitud reflexiva que en principio tome conciencia acerca de las respuestas a estos interrogantes: ¿para qué?, ¿en base a qué?, ¿bajo qué modelos plantear su práctica?, ¿cuál es la incidencia de estos procesos tecnológicos -entornos, mediaciones- en las propuestas educativas?, ¿qué y cómo potenciar procesos cognitivos complejos?

Por otro lado, retomando las palabras de Area Moreira (2001) "Los ordenadores no cambian la educación, pero los profesores si", por lo tanto el valor del diseño de formación va más allá del entorno tecnológico, dándole a éste su espacio como ambiente de aprendizaje -espacio simbólico de interacción-, creado a partir de la mediación de las TIC.

Es también revalorizar no solo el contenido sino el conocimiento didáctico del contenido. La información se transforma en conocimiento en tanto y en 
cuanto se pongan en juego estrategias de enseñanza que permitan actuar sobre ella, procesarla, confrontarla con otras fuentes de información, con nuestros propios conocimientos y los de los demás. Es posibilitar la discusión, el debate y el diálogo a fin de construir consensos, donde el solo hecho de afirmar "... mi conclusión final es que me llevo un montón de nuevos interrogantes", se transforma en la clave de regulación de los aprendizajes propios y de todos.

\section{Referencias bibliográficas}

- Área Moreira, M. (Coord). (2001). Educar en la Sociedad de la Información. Bilbao: Desclée de Brouwer, S.A.

- $\quad$ Diaz Barriga, F. y Hernández Rojas, G. (2001). Estrategias docentes para un aprendizaje significativo. Una interpretación constructivista. México D.F.: McGraw-Hill.

- Escudero, C. (2009). Una mirada alternativa acerca del residuo cognitivo cuando se introducen nuevas tecnologías. El caso de la resolución de problemas en ciencias. Teoría de la Educación: Educación y Cultura en la Sociedad de la Información, 10 (1).

- Forestello, R. y Gallino, M. (2009). Reflexiones en torno a la coherencia pedagógicodidáctica de la enseñanza como práctica mediada por TIC. Revista de Ciencias de la Educación, 5 (1).

- Gimeno Sacristán, J. (2005). La educación que aún es posible. Ensayos acerca de la cultura para la educación. Madrid: Morata.

- Levinson, R. (2006). Towards a Theoretical Framework for Teaching Controversial Socioscientific Issues. International Journal of Science Education 28 (10), pp: 1201-1224

- Occelli, M.; Garcia, L.; Biber, P. y Valeiras, N. (2009). Las plantas transgénicas desde el Aprendizaje Basado en Problemas: Una propuesta de capacitación docente mediada por las Tecnologías de la Información y la Comunicación. Memorias del II Encuentro de Innovadores Críticos. ADBiA, San Juan.

- Occelli, M. y Vázquez Abad, J. (2010). Teacher training through the solution of a biotechnological problem in a computer supported collaborative learning environment. Virtualidad, Educación y Ciencia, 1 (1), pp: 51-63.

- Onrubia, J. (2005). Aprender y enseñar en entornos virtuales: actividad conjunta, ayuda pedagógica y construcción del conocimiento. RED. Revista de Educación a Distancia, número monográfico II. Consultado el 9 de Febrero de 2005 en http://www.um.es/ead/ red/M2/

- Pea, R. D. (1993). Prácticas de inteligencia distribuida y diseños para la educación. En: Salomon, G. (Comp). Cogniciones distribuidas. Buenos Aires: Colección Agenda Educativa. Amorrortu Editores S. A.

- Rodríguez Arocho, W. (2001). La valoración de las funciones cognoscitivas en la zona de desarrollo próximo. EDUCERE, 5 (15).

- Salomon, G. (Comp.). (1993). Cogniciones distribuidas. Consideraciones psicológicas y educativas. Buenos Aires: Amarrortu.

- Vigotsky, L. (1988 a). El desarrollo de los procesos psicológicos superiores. México D.F.: Crítica.

- Vigotsky, L. (1988 b). Pensamiento y lenguaje. Teoría del desarrollo cultural de las funciones psíquicas. Buenos Aires: La Pléyade. 